\title{
The Learning Study Process -A Collaborative Way to Develop the Use of Contrast of Critical Aspects in Preschool Educational Practice
}

\author{
Agneta Ljung-Djärf \\ Kristianstad University, 29188 Kristianstad, Sweden \\ Tel: 46 44-203-252Ｅ-mail: agneta.ljung-djarf@kr.se
}

Received: Nov. 21, 2012 Accepted: December 11, 2012 Published: February 1, 2013

doi:10.5296/jse.v3i1.2743ＵRL: http://dx.doi.org/10.5296/jse.v3i1.2743

\begin{abstract}
The aim of the study is to investigate how contrast of critical aspects of the object of learning could be used to improve children's ways of discerning the mathematical concept twice as, by analyzing an learning study project in Swedish preschool. The empirical material consisted of verbatim transcriptions of a screening $(n=24)$, three video-documented interventions, and 132 individual test forms $(n=44)$ completed before and after a teaching activity and four weeks later. By letting different aspects related to the intended object of learning appear as variant or invariant, different patterns of variation were used in developing the interventions. The results shows differences related to the children's learning in each of the three cycles. It indicates that a conscious use of simultaneity and contrast of identified critical aspects seems successful in stimulating children's short- as well as long-term learning. Thus, the results of the study suggest that variation theory can serve as a guiding principle in the development of pedagogical design in preschool. The study also indicates the need for more LS projects on the application of variation theory in preschool educational practice.
\end{abstract}

Keywords: Contrast of critical aspects, Learning study, Variation theory, Twice as, Preschool 


\section{Introduction and aim}

This article is reporting on a learning study (LS) conducted in a Swedlish preschool. The theoretical point of departure of the project was variation theory (Holmqvist, Gustavsson \& Wernberg, 2008; Marton \& Booth, 1997; Runesson, 1999, 2006; Lo, 2012; Lo \& Marton, 2012). Many studies on this topic have been conducted, especially in Asian counties as well as in the United States of America, the United Kingdom, and Sweden. Previous learning studies have focused mainly on school contexts and shown that the LS model based on variation theory is a useful tool for developing and improving learning and understanding of a concept or phenomenon (e.g., Holmqvist \& Lindgren, 2009; Wernberg, 2009; Wood, 2010). The studies also showed that variation theory is useful for improving teaching practice and developing teachers' knowledge about learning (e.g., Carlgren, 2010; Chan, 2010; Gustavsson, 2008; Pang, 2006; Runesson, 2010). During an international process of testing the LS model it was found to improve learning, reduce the gap between high and low achievers, and contribute to teachers' and researchers' learning about teaching and learning (Lo, 2012; Lo \& Marton, 2012).

International publications have also reported on research intended to develop education and learning in preschool settings through the use of LS (e.g., Holmqvist, Tullgren \& Brante, 2010; Holmqvist, Tullgren \& Brante, 2011; Ljung-Djärf \& Magnusson, 2010; Ljung-Djärf \& Holmqvist, 2012). These studies shows that LS design may fit into a preschool context but needs to be adjusted to suit preschool culture and context and preschool children's conditions and needs. The four main features of a school-based LS that seemed to need adapting for preschool activity were the approach to learning, ways of guiding the children, the content on which the teachers focus, and ways of assessing learning outcome. The conclusion was that the LS model is possible to apply and adjust the model to preschool settings to deepen the teachers' understanding about children's learning and that the tradition of seeing preschool learning as doing, having fun, or playing should be challenged. An educational practice that combines play and learning in a more purposeful way has to be developed, as do well as better methods of assessing children's learning (Ljung-Djärf \& Holmqvist Olander, 2012). The need for further international studies in early childhood remains.

The aim of the study is to investigate how contrast of critical aspects of the object of learning could be used to improve children's ways of discerning the mathematical concept twice as, by analyzing an LS project in Swedish preschool. The purpose is to contribute to an expanded understanding of application of LS and variation theory in preschool educational practice to meet contemporary demands on preschool teachers for an increased focus on content and cognitive outcomes (The Swedish National Agency for Education, 2004; The Swedish National Agency for Education, 2010).

\section{Theoretical assumptions - variation theory}

From the perspective of variation theory, learning is seen as a more developed way of understanding or seeing a phenomenon (Holmqvist, Gustavsson, \& Wernberg, 2008; Marton \& Booth, 1997; Runesson, 1999, 2006; Lo, 2012; Lo \& Marton, 2012). Variation theory developed from phenomenography (Marton, Dahlgren, Svensson, \& Säljö, 1977). The 
theoretical assumptions are that all phenomena can be perceived in qualitatively different ways and the observer's way of experiencing is united with the phenomenon. A description of expressed qualitative different experiences of the same phenomena can be used to define what the critical aspects of the object of learning are, for example, what needs to be perceived in order to discern specific features of the phenomenon. Such information is crucial to understanding what it takes to learn a specified object of learning and how to design learning situations.

Variation theory is based on the concepts of discernment, simultaneity, and variation, which are seen as intertwined and necessary in a learning situation to develop learning. To understand a phenomenon one has to discern its critical aspects. If, as in this case, the object of learning is the concept twice as, critical aspects could be, for example, the concept states something related to quantity, this quantity is about more than the original, and it is exactly two times the original. Identifying a critical aspect depends on the relationship between the learning object and the learning person, on the persons' previous experiences and knowledge.

When an aspect is discerned it is no longer critical for the person. It is instead an aspect that can be used to define and separate the phenomenon from other phenomena.

The assumption is that to discern something a person has to experience variation (what something is and is not) simultaneously in order to become aware of the features that the phenomenon consists of. The variation can be experienced in the situation or as memories of earlier experiences related to the object to be learned. Experiencing differences has a bearing on what a person discerns and thus what they are able to learn. When a person learns a new concept, the learning outcome is related to the aspects offered in the learning situation, and the way simultaneity is used to allow the learner to discern the aspects needed to understand the phenomenon. For example, discerning what a ripe strawberry is requires discernment of strawberries of different degrees of ripeness. Differences in different degree of ripeness can be discerned by focusing on appearance, taste, or texture. Critical aspects of appearance could be size or color. If, however, all the strawberries looked the same, taste and texture would have to be focused on. The ways in which aspects appear as variant or invariant in the learning situation create a pattern of variation. In an LS project, such patterns of variation are used to try to develop and improve the learner's ways of discerning an intended object of learning.

\section{Methodological framework — learning study}

An LS is a type of action research that combines variation theory with the concept of lesson study (e.g., Lewis, 2002; Yoshida \& Fernandez, 2004). In such a project, researchers and teachers work as a team to generate, share, develop and implement knowledge about teaching with the aid of variation theory concepts and notions. By that, it is a project built up by a joint reflection on the classroom practice through research ventures.

The LS is designed is in a specified way (e.g., Holmqvist, 2006; Häggström, Bergqvist, Hansson, Kullberg, \& Magnusson, 2012; Marton \& Tsui, 2004). First the object of learning, that which the learner is intended to discern and learn about during the process, is defined. 


\section{Macrothink Institute ${ }^{\mathrm{TM}}$}

Then a screening is done to identify qualitative different ways of discerning the object of learning. This information is used to define what the critical aspects of the object of learning appear to be. Such information is used in designing the interventions and the test used to assess the children's ways of discerning the object of learning. The test can be designed as an interview, an observation, or a practical or written task. The same test and the routines are used during the various LS cycles.

An LS project typically comprises three cycles, but can have more or fewer. Each cycle contains of four specified steps. During the process, the structure of the steps remains the same but the way of implementing some of them changes.

The first step or pre-test is done to discover what the pupils participating in the first cycle already know about the intended object of learning. The test results are analyzed qualitatively and/or quantitatively.

The second step is to design and implement an intervention in the form of a teaching activity. All the participating teachers and researchers develop the activities, which are designed to challenge and develop understanding and learning. One teacher implements the activity with the children participating in the cycle.

In the third step, a post-test is used to discover what the children know after the teaching activity so as to identify differences in their understanding before and after the intervention. Based on the post-test, it is possible to say something about the children's short-term learning, for example, what they seems to have discerned based on the teaching activity and what aspects still appear to be critical. About four weeks later, a delayed post-test is conducted to identify the extent of the children's long-term learning.

During the fourth step, the participating teachers and researchers evaluate the test results, discussing whether or how the children's learning and understanding may have changed and which aspects of the object of learning still appears to be difficult for the them to capture. During this analysis and discussion, the variation theory's concepts of discernment, simultaneity, and variation serve as guiding principles. A somewhat different teaching activity is designed.

The next cycle starts with a pre-test (step 1), and a second teacher implements the second teaching activity (step 2) with another group of children/pupils and so on (step 3-4). All parts of the process are documented, mainly with the aid of a video recorder.

\section{Method and material}

In this study, a group of teachers and researchers worked in an iterative process to improve preschool educational practice when teaching the concept twice as, by using a three-cycle LS. The research question is: How can contrast of critical aspects be used to improve preschoolers' discernment of a basic mathematical concept?

\subsection{The participants}

The participating teachers $(n=5)$ had long experience working in preschool but no particular 
mathematic education beyond their teacher training. Each teacher participated in four group planning meetings and some of them implemented a teaching activity.

The participating children $(n=68)$ were between five and six years of age (Table 1$)$. They were divided into four different groups with one group participating in the screening and one in cycles $\mathrm{A}, \mathrm{B}$, and $\mathrm{C}$ respectively.

Table 1. Characteristics of participating children

\begin{tabular}{|l|l|l|l|l|}
\hline & $\begin{array}{l}\text { Screening } \\
(\mathrm{n}=24)\end{array}$ & $\begin{array}{l}\text { Cycle A } \\
(\mathrm{n}=14)\end{array}$ & $\begin{array}{l}\text { Cycle B } \\
(\mathrm{n}=13)\end{array}$ & $\begin{array}{l}\text { Cycle } \mathrm{l} \\
(\mathrm{n}=17)\end{array}$ \\
\hline Mean age (months) & 73 & 75 & 75 & 74 \\
\hline Min-max age (months) & $69-79$ & $70-81$ & $72-80$ & $70-80$ \\
\hline Girls & 14 & 4 & 7 & 5 \\
\hline Boys & 10 & 10 & 6 & 12 \\
\hline
\end{tabular}

Ethical considerations, as described by The Swedish research council (2011), guided the process. All participants including parents, teachers, management, and children were continuously informed about the aims of the study, the use of the data, and their rights to confidentiality and to withdraw from participation.

\subsection{Identifying the intended object of learning and its critical aspects}

The project started with an introduction of the LS methodology; the teachers read the same foundational book on the topic and participated in a lecture. There was also a session that included a defining of the object of learning. The teachers identified the concept twice as as being challenging to teach about and help the children understand.

The initial screening, which was designed as an individual practical test, was used to discern critical aspects of the chosen object of learning. Some of the teachers carried out the screening and during it read instructions and showed examples of the screening activities to the children. The children ( $n=24)$ were asked to do the following:

1. Cut a string that was twice as long

2. Build tower out of wooden blocks that was twice as high

3. Put twice as many pencils on the table

4. Pour twice as much water in another glass

The screening revealed that some children seemed to have no idea of the concept. Among those who had some ideas, three main ways of managing the concept appeared. The most common was that twice as was the same as. These children cut the string the same length, built the tower to the same height, placed the same number of pencils on the table or poured as much water in the glass, as the teacher had. Some children managed the concept as one 
more or one bit more. These children cut the string a little bit longer, built the tower one block higher, put one more pencil on the table, or poured some more water in the glass than the teachers had. A few children managed the concept as twice as long, high, or many. Critical aspects not yet discerned by most of the children were as follows: the appearance of an initial quantity is critical for the appearance of twice as and two times the initial quantity makes a twice as. These insights formed the basis for the next stage of the project.

\subsection{Constructing the test}

During the study, three written tests were conducted individually with each child, a pre-, a post- and a delayed post-test. They were based on variation theory to illuminate the critical aspects of the children's understanding. The test had seven questions and a total of seven points could be earned. The test questions related to different uses of twice as: twice as many (question 1, 2, 6 and 7), twice as high (question 3), twice as long (question 4) and twice as much (question 5). Questions 1 to 5 had four specified alternative response options and question 6 and 7 were open-ended.

The tests were conducted with all the children (4-8) in the group doing each test at the same time. The teacher followed a pre-determined routine, reading the instructions and questions while a picture of the task was displayed on the board. The same test and routines were used in pre-, post-, and delayed post-tests.

\subsection{The empirical material}

The empirical material consisted of verbatim transcriptions of a screening $(n=24)$, three video-documented interventions, and 132 individual test forms $(n=44)$ completed before and after the teaching activity and four weeks later. During the analyses, the transcripts and test results were scrutinized in a number of readings and re-readings in which the original video recordings were frequently consulted.

\section{Results}

During the first teaching activity (cycle A), the children were placed on the floor in a semicircle with the teacher in front of them. The teacher used small wooden blocks and the children to illustrate the notion of twice as. The children participated by responding, making suggestions, and serving as examples of twice as. The activity was used to illustrate the meaning of twice as many.

In the second teaching activity (cycle B), the teacher again used small wooden blocks, but now also gave each child 12 wooden blocks. As in cycle A, the children were on the floor with the teacher in front of them. The children participated by responding and making suggestions related to the teacher and by putting the wooden blocks in front of themselves in responses to the teacher's instructions. Twice as was used in the meaning of twice as many, long, and high. The children actively participated and placed the wooden blocks all over the floor.

During the third intervention (cycle C), the children were placed at tables in front of the teacher and given a piece of paper that was half blue and half red. They were also each given 
four blue and eight red pieces of Lego. Twice as was used only in the meaning of twice as many. The concept of as many was used as contrast in the same way as in cycle B. The teacher managed the situation and the children participated by responding, making suggestions, and placing the same as (blue) pieces and twice as (red pieces) on their piece of paper. The children were asked to put as many blue pieces of Lego on the blue side of their paper as the teacher had placed on the blue side of her paper, which was on the board. Then, they were to place twice as many red pieces on the red side of their paper. Initially, the teacher demonstrated what to do and then the children tried by themselves.

\subsection{Contrast of critical aspects}

During the teaching activities, different representations, appearance of the representations, and ways of illustrating the intended object of learning were made variant or invariant. This was done in an attempt to make the contrast of the critical aspects of the object of learning, twice as, visible and clear to the children. Different patterns of variation were created and used; these are summarized in Table 2.

Table 2. Patterns of variation

\begin{tabular}{|c|c|c|c|}
\hline & Cycle A & Cycle B & Cycle C \\
\hline $\begin{array}{l}\text { Used } \\
\text { representations }\end{array}$ & $\begin{array}{l}\text { Variant - wooden } \\
\text { blocks and children }\end{array}$ & $\begin{array}{l}\text { Invariant }- \text { only wooden } \\
\text { blocks }\end{array}$ & $\begin{array}{l}\text { Invariant - only pieces of } \\
\text { Lego }\end{array}$ \\
\hline $\begin{array}{l}\text { Appearance of } \\
\text { used } \\
\text { representation/s }\end{array}$ & $\begin{array}{l}\text { Invariant - the } \\
\text { appearance of each of } \\
\text { the two representations } \\
\text { was the same, } \\
\text { illustrating the initial } \\
\text { quantity and twice as } \\
\text { (natural colored wooden } \\
\text { blocks). }\end{array}$ & $\begin{array}{l}\text { Invariant }- \text { the appearance } \\
\text { was the same illustrating the } \\
\text { initial quantity and twice as } \\
\text { (natural colored wooden } \\
\text { blocks). The blocks were } \\
\text { placed in front of each child to } \\
\text { illustrate the initial quantity and } \\
\text { the quantity of twice as } \\
\text { simultaneously. }\end{array}$ & $\begin{array}{l}\text { Variant - blue and red } \\
\text { pieces and a bi-colored } \\
\text { paper were used to separate } \\
\text { the initial quantity and } \\
\text { twice as and illustrate the } \\
\text { initial quantity and the } \\
\text { quantity of twice as } \\
\text { simultaneously. }\end{array}$ \\
\hline $\begin{array}{l}\text { Ways of } \\
\text { illustrating twice } \\
\text { as by the use of the } \\
\text { representation/s }\end{array}$ & $\begin{array}{l}\text { Invariant — only twice } \\
\text { as many }\end{array}$ & $\begin{array}{l}\text { Variant - twice as many, long } \\
\text { and high }\end{array}$ & $\begin{array}{l}\text { Invariant - only twice as } \\
\text { many }\end{array}$ \\
\hline
\end{tabular}

\subsection{The children's ways of discerning the object of learning}

The children's ways of discerning the concept was analyzed based on the results of the pre-, post- and delayed post-test. The mean points, range and percentage increase of these tests are summarized at a group level in Table 3. 


\section{Macrothink}

Table 3. Mean points, range and percentage increase of the test results (max 7.0)

\begin{tabular}{|l|l|l|l|l|l|l|l|l|l|}
\hline & \multicolumn{7}{l}{ Cycle A } & \multicolumn{7}{l|}{ Cycle B } & \multicolumn{2}{l|}{ lycle C } \\
\hline & Mean & Range & Increase & Mean & Range & Increase & Mean & Range & Increase \\
\hline Pre-test & 1.4 & $0-6$ & - & 1.2 & $0-7$ & - & 0.7 & $0-3$ & \\
\hline Post-test & 1.7 & $0-7$ & $21 \%$ & 1.3 & $0-7$ & $8 \%$ & 2.1 & $0-6$ & $200 \%$ \\
\hline $\begin{array}{l}\text { Delayed } \\
\text { post-test }\end{array}$ & 1.4 & $0-7$ & $0 \%$ & 1.8 & $0-7$ & $67 \%$ & 2 & $0-6$ & $186 \%$ \\
\hline
\end{tabular}

The children's short-term learning (pre- to post-tests) increased in all three cycles, while the long-term learning (pre- to delayed post-test) remained the same in cycle A and increased in cycles B and C. As shown in Table 3, the extent of the increases varied and was greatest in cycle $\mathrm{C}$. In all groups, there were a number of children whose results improved as well as declined between the pre- and the delayed post-test.

In all groups, there were children who scored no points on the test. Analysis revealed a pattern of these children clinging throughout the process to their initial way of discerning the concept, mostly seeing twice as in terms of same as or to a lesser extent as one more.

\subsection{Analysis}

How can these differences in the children's discernment of twice as be understood? In the first teaching activity we used a variation of representations (natural colored wooden blocks and children) but let the appearance of representations used appear the same, either as they illustrated the initial quantity or twice as of it. Ways of illustrating twice as were held invariant by using only the meaning of twice as many. The increase of the mean points from the pre- to the post-test was about 21\%. During the first intervention (cycle A), the teacher tried to exemplify the notion of twice as with the use of wooden blocks. But, the appearance and use of these representations did not create separation of the initial quantity from twice as the initial quantity; neither did the teacher's explanations. The focus was on counting and whether something was right or wrong, as seen in Excerpt 1.

Excerpt 1

Teacher (T) Two wooden blocks, but now it's like this, that I want to double the number of wooden blocks on that side. How many should I put there? [Points next to the two wood blocks lying on the floor]. Henrik?

Henrik Four.

T How then, did you know this? How do you know? You just knew it?

Henrik Mmmm.

$\mathrm{T}$ Because it is quite right; there are two [points at the first two wooden blocks. Puts two 
wooden blocks by their side while counting] one, two. Now there are as many, right? [pointing at the two piles of wooden blocks]

\section{ChildrenMmmm.}

\section{$\mathrm{T}$ Twice as many makes four.}

During this teaching activity though, there was an attempt to use generalization to show that twice as means the same thing whether it refers to wooden blocks or children.

In an attempt to improve the results in the next intervention, we changed strategy and used only one sort of representation (natural colored wooden blocks) but varied the ways of illustrating twice as by using the blocks to illustrate different aspects of twice as (twice as many, long, and high). Even though there was an attempt to use the wooden blocks to illustrate the initial quantity as well as the quantity of twice as, it seems that the appearance and use of representations did not separate the initial quantity from twice as the initial quantity. The teacher, whose focus was on same as and twice as, did not make a clear connection between the initial quantity and twice as, as seen in Excerpt 2.

\section{Excerpt 2}

$\mathrm{T}$ How many wooden blocks do I have?

ChildrenTwo.

$\mathrm{T}$ And now, you are going to figure out; you also take two of your wooden blocks and put them like this [pointing at her two wood blocks]

Children[places two wood blocks in front of themselves]

$\mathrm{T}$ Two pieces of wooden blocks and place them in front of you. Think about it; now you have two wooden blocks but you should have twice as many. How many wooden blocks will you add?

Child Two.

$\mathrm{T}$ No, remember, you do it and then we will look at it and see. First, you have your two wooden blocks and then on the side, you lay twice as many.

Children[place wooden blocks on the floor in front of them. Some places two, some four and some uses all 12]

$\mathrm{T}$ You have your two, and beside them you put twice as many.

$[\ldots]$

T Max, you have your two, and where did you put twice as many?

Max Here [point at eight wood blocks placed in a pile]

$\mathrm{T}$ How many did you put there?

Max One, two, three, four, five, six, seven, eight. Eight. 
T You've added eight.

$[\ldots]$

$\mathrm{T}$ Now look really closely at me and I'll put the correct answer. I have two and I put twice as many. I add; we count together [puts four wooden blocks beside the initial two]. One, two, three, four. I took as many and as many one more time. So, twice as many as two is four.

During this teaching activity generalization was also introduced by the use of different meanings (many, long, high). This time the increase from the pre- to the post-test test was lower, only $8 \%$.

In the third teaching activity, we used both invariation in representations (pieces of Lego) and variation in the appearance of the Lego pieces (blue and red) together with a bi-colored paper to clearly separate the initial quantity from the quantity of twice as. This way of illustrating twice as by using pieces of Lego was also held invariant (twice as many). The attempt was to clearly separate the appearance of the initial quantity (blue) from twice as the initial quantity (red). By using such representations, it was possible for the teacher to use contrast to direct the children's focus towards the relationship between theses quantities as seen in Excerpt 3.

\section{Excerpt 3}

$\mathrm{T}$ Before, we were talking about the same number of, right?

ChildrenYes.

T When I put up one, you put up one? When I put up two, you put up?

ChildrenTwo.

$\mathrm{T} \quad$ Yes, good. If I put up three, you put up?

ChildrenThree.

$\mathrm{T}$ And so on. Now it gets a little trickier because now let's talk about twice as. Here it comes, so listen carefully. Now I put up two blue pieces of Lego on the blue paper. Can you do the same? [Puts two blue pieces on her blue paper, which is on the board].

Children[put two pieces of Lego on their blue paper]

$\mathrm{T}$ Now, I should put twice as many red pieces on the red paper. I will put twice as many red ones on the red paper. It will be like this. First I put same as the first [puts two red pieces on the red paper] and then the same number of one more time [adds two more red pieces on the red paper]. Here you go.

Children [put four red pieces of Lego on their red paper]

$\mathrm{T}$ Now you have added twice as many red as blue as I have also done on the board. We had two blue pieces of Lego and then we put two pieces of red once and then the same as one more time. Are you with me?

Children Yeah. 


\section{Macrothink}

Generalization was not used during this intervention. When using this pattern of variation the improvement increased $200 \%$. As a result, the study concluded that the patterns of variation used in cycle $\mathrm{C}$ seem to be most successful. How can this be understood by the variation theory?

Intervention A assumed, or even took for granted, that the children could easily or automatically discern the main principle of twice as more or less when the teacher used the concept and showing some examples. By the use of generalization the teacher tried to illustrate that the same principle can apply to different representations (wooden block and children). In line with the theoretical perspective (e.g., Lo, 2012; Lo \& Marton, 2012), the analysis suggests that it is basic to initially focus on differences rather than sameness because generalization cannot help the learner to discern what is critical.

During the second intervention (cycle B), the natural colored wooden blocks were used to make the children separate an initial quantity from twice as the initial quantity by seeing them simultaneously. However, because the area became quite messy when lots of wooden blocks were placed on the floor in a somewhat unstructured way, it was not easy for the children to separate which wooden blocks illustrated the initial quantity and which illustrated twice as and because of this. It was also difficult for them to discern the contrast between the initial quantity and twice as. According to variation theory, critical features can be discerned if they vary while noncritical features are invariant but if two aspects vary together they will fuse (Lo, 2012; Lo \& Marton, 2012). When the teacher talked about twice as many, long, and high at the same time, it might have confused some children. According to variation theory, it is crucial to let only one aspect related to the object of learning vary at a time because more may make it difficult to discern what is intended.

In the last cycle (cycle $\mathrm{C}$ ), we tried to make it possible to discern the main principle by using one sort of representation (pieces of Lego) in two different colors (blue and red) together with a bi-colored paper to separate the initial quantity from the quantity of twice as simultaneously and to make the contrast between both clear. During this intervention generalization as it comes to another meaning (e.g., much, long or high) and other representations was not made. According to the test results this cycle seemed to be successful. The use of separation, contrast, and generalization during the interventions is summarized in Table 4. 
Table 4. The use of separation, contrast and generalization during the interventions

\begin{tabular}{|c|c|c|c|}
\hline & Cycle A & Cycle B & Cycle C \\
\hline Separation & $\begin{array}{l}\text { None - the appearance } \\
\text { and use of representations } \\
\text { did not separate the initial } \\
\text { quantity from twice as the } \\
\text { initial quantity. }\end{array}$ & $\begin{array}{l}\text { None - the appearance and } \\
\text { use of representations did not } \\
\text { separate the initial quantity } \\
\text { from twice as the initial } \\
\text { quantity. }\end{array}$ & $\begin{array}{l}\text { Separation - blue and red } \\
\text { pieces of Lego were used to } \\
\text { separate the initial quantity } \\
\text { from twice as the initial } \\
\text { quantity. }\end{array}$ \\
\hline Contrast & $\begin{array}{l}\text { None - the focus was on } \\
\text { twice as. }\end{array}$ & $\begin{array}{l}\text { None - the focus was on } \\
\text { same as and twice as, but the } \\
\text { relation of the initial quantity } \\
\text { as critical for the appearance } \\
\text { of twice as was not made } \\
\text { clear. }\end{array}$ & $\begin{array}{l}\text { Contrast - the focus was on } \\
\text { the rellation of the initial } \\
\text { quantity as critical for the } \\
\text { appearance of twice as by the } \\
\text { use of the different colored } \\
\text { pieces of Lego. }\end{array}$ \\
\hline Generalization & $\begin{array}{l}\text { Generalization }- \text { was } \\
\text { introduced by different } \\
\text { sorts of representations } \\
\text { (wooden blocks and } \\
\text { children). }\end{array}$ & $\begin{array}{l}\text { Generalization - was } \\
\text { introduced by demonstrating } \\
\text { different meanings (many, } \\
\text { long, high). }\end{array}$ & $\begin{array}{l}\text { None - generalization was } \\
\text { not introduced. }\end{array}$ \\
\hline
\end{tabular}

The study has investigated how contrast of critical aspects can be used to improve preschoolers' discernment of a basic mathematical concept. The result indicates that a conscious use of separation and contrast related to a critical aspect of an intended object of learning seems to improve the children's ways of discerning the intended object of learning. This also indicates that generalization should be introduced after contrast because generalization does not seem to help the learners to discern what is critical.

\section{Discussion}

In this study, a three-cycle LS model built on the variation theory has been used to develop three somewhat different teaching activities focusing on the same intended object of learning: twice as. During this process, the representations used, the appearance of these representations, and ways of using them to illustrate the concept of twice as appeared as variant or as invariant. This created three different patterns of variation. The results suggest differences in how successful different pattern of variation are. Using contrast of critical aspects, limiting what varies, and introducing generalization only when the critical aspect has been discerned seemed the most successful way to stimulate children's short- and long-term learning.

The result is consistent with previous LS in preschool (e.g., Holmqvist et al., 2010; Holmqvist et al., 2011; Ljung-Djärf \& Magnusson, 2010) as well as school contexts (e.g., Carlgren, 2010; Chan, 2010; Gustavsson, 2008; Holmqvist \& Lindgren, 2009; Wernberg, 2009; Wood, 2010; Pang, 2006). But, the analyzed material consists of one LS project that involved one researcher, five preschool teachers, and 68 children, which limits the ability to 
draw general conclusions. However, the intention was not to establish a set of rules for the use of LS, but to raise questions about the use of contrast of critical aspects of an object of learning to improve children's discernment of a basic mathematical concept. The related purpose was to investigate the LS model as having the potential to meet contemporary demands on preschool teachers for an increased focus on content and cognitive outcomes.

This study, as well as Ljung-Djärf and Magnuson (2010), indicates that the complexity of a focused object of learning appears to be too difficult for many children to grasp based on only one teaching activity. It is hardly new to say that education is not a linear process with learning occurring automatically or mechanically. Providing what appear to be, from a variation theory approach, the necessary conditions for learning does not guarantee that learning will take place. The study has shown that some children discern the object of learning and some do not. It also shows that some children discern it even if, from a variation theory approach, the necessary conditions are not provided. There are many possible contextual and/or individual explanations for this. Not discerning could be connected to the children having a focus than that the teacher intended, having problems with language comprehension, or being distracted. Or the focused critical aspects and patterns of variation used may not have been suitable. On the other hand, children may have discerned the concept because they recalled conditions from their past that provided a contrast to what they experienced during the intervention. But the study does point to the importance of providing simultaneity and contrast and of not taking for granted that the children having had experiences that will help them to discern the necessary contrast by themselves.

The LS process has been characterized by collaboratively generated, developed, and implemented knowledge about the use of variation theory concepts to challenge children's skills and knowledge in relation to a specified content. It also examined if and how the LS model could be used as a systematic approach to develop teachers' readiness to govern content-oriented activities and teaching based on awareness of children's perspectives.

Recently, researchers have highlighted the need for such a systematic approach in Swedish preschool education and have criticized it for being a "doing culture" with its main focus on what to do instead of what to learn (Pramling Samuelsson \& Pramling, 2008), and thereby lacking a concretization of learning content. This study shows that the LS model might serve to meet the need to develop a conscious approach to preschool educational practice that highlights and builds on children's experiences of an object of learning and simultaneously provides information and concepts of significance.

By that the LS model might serve as a tool to capture the possible impact of using variation theory concepts as guiding principles in preschool education practice. Such insights are applicable in content-oriented activities, for example, within thematic work or during creative and/or outdoor activities. The results of the study indicate it might be worth considering using the LS model as a tool to improve preschool teachers' readiness to enable children to discern aspects of their surrounding world. But, it also indicates the need for more LS projects on the application of variation theory in preschool educational practice.

\section{Acknowledgement}

I would like to thank the participating teachers who generously shared their time and teaching, 
and my research team Learning Design (LeaD) at Kristianstad University, Sweden, for encouragement and support.

\section{References}

Carlgren, I. (2010). Learning studies as a way to transform teachers' work from a habitual to an epistemic practice. Paper presented at World association of lesson studies (WALS) 2010 conference, Brunei Darussalam.

Chan, W. Y. (2010). How to improve students' engagement and maximize their learning insights from a learning study in English language art. Paper presented at World association of lesson studies (WALS) 2010 conference, Brunei Darussalam.

Gustavsson, L. (2008). Becoming a better teacher: Ways of dealing with the content made a topic of conversation among teachers. PhP Thesis, University of Umeå, Sweden.

Häggström, J., Bergqvist, M., Hansson, H., Kullberg, A., \& Magnusson, J. (2012). Learning study - en guide [Learning study - a guide]. Göteborg: Göteborgs universitet.

Holmqvist, M., \& Lindgren, G. (2009). Students learning English as seicond language: An applied linguistics learning study. Problems of Education in the 21st Century, 18, 86-96.

Holmqvist, M. (2006). Lärande i skolan: Learning study som skolutvecklingsmodell [Learning at school: Learning study as school development]. Lund: Studentlitteratur. Holmqvist, M., Gustavsson, L., \& Wernberg, A. (2007). Generative learning: Learning beyond the learning situation. Educational Action Research, 15(2), 181-208. http://dx.doi.org/10.1080/09650790701314684

Holmqvist, M., Gustavsson, L., \& Wernberg, A. (2008). Variation theory - An organizing principle to guide design research in education. In: Kelly A E, Lesh R \& Baek J (Eds.), Handbook of design research methods in education. New York: Routledge (pp. 111-30).

Holmqvist, M., Tullgren, C., \& Brante, G. (2010). Using Variation theory to analyse what preschool children experience exemplified by wholes and parts as the object of learning. In J.V. Carrasquero, M. Holmqvist, D. McEachron, A. Tremante, \& F. Welsch (Eds.), Proceedings. I, 8-11. Orlando: International Institute of informatics and Systemics.

Holmqvist, M., Tullgren, C., \& Brante, G. (2011). The object of learning: before, during and after a learning situation. Journal of Systemics, Cybernetics and Informatics, 9(2), 67-73.

Lewis, C. (2002). Lesson study: A handbook of teacher-led instructional change. Philadelphia, PA: Research for Better schools, Inc.

Ljung-Djärf, A., \& Holmqvist Olander, M. (2012). Using learning study to understand preschoolers' learning: Challenges and possibilities. International Journal of Early Childhood, 45(1). http://dx.doi.org/10.1007/s13158-012-0067-9

Ljung-Djärf, A., \& Magnusson, A. (2010). Pre-school children's sustainable thinking: The organic decomposition process as intended object of learning at pre-school. Paper presented at World association of lesson studies (WALS) 2010 Conference, Brunei Darussalam. 
Lo, M. L. \& Marton, F. (2012). Towards a science of the art of teaching: Using Variation theory as a guiding principle of pedagogical design. International Journal for Lesson and Learning Studies, 1(1), 7-22. http://dx.doi.org/10.1108/20468251211179678

Lo, M. L. (2012). Variation theory and the improvement of teaching and learning. Göteborg: Acta Universitatas Gothenburgensis.

Marton, F., \& Booth, S. (1997). Learning and awareness. Mahwah, NJ: Erlbaum Associates.

Marton, F., \& Tsui, A. B. (2004). Classroom discourse and the space of learning. London: Lawrence Erlbaum Associates.

Marton, F., Dahlgren, L-O., Svensson, L., \& Säljö, R. (1977). Inlärning och omvärldsuppfattning [Learning and conceptions of reality]. Stockholm: Almqvist \& Wiksell.

Pang, M. F. (2006). The use of learning study to enhance teacher professional learning in $\begin{array}{llll}\text { Hong Kong. Teaching } \quad \text { Education, } & \text { 17(1), }\end{array}$ http://dx.doi.org/10.1080/10476210500527915

Runesson, U. (1999). Variationens pedagogik: skilda sätt att behandla ett matematiskt innehåll [The pedagogy of variation: different ways of handling mathematical topic]. $\mathrm{PhP}$ Thesis, University of Gothenburg, Sweden.

Runesson, U. (2010). Learning study - a knowledge production for teachers? Paper presented at World association of lesson studies (WALS) 2010 Conference, Brunei Darussalam.

The Swedish National Agency for Education. (2004). Förskola i brytningstid. Nationell utvärdering av förskolan. Rapport 239, 2004. Stockholm: Fritzes.

The Swedish National Agency for Education. (2010). Curriculum for the preschool, lpfö 98/2010. Stockholm: Fritzes.

The Swedish Research Council. (2011). Forskningsetiska principer inom humanistisk-samhällsvetenskaplig forskning [Ethic principles in social science research]. Available at: http://www.codex.vr.se/texts/HSFR.pdf (accessed 7 February 2012).

Wernberg, A. (2009). Lärandets objekt: Vad elever förväntas lära sig, vad görs möjligt för dem att lära och vad de faktiskt lär sig under lektionerna [The object of learning. What students are expected to learn, what is made possible for them to learn and what they actually learn]. PhP Thesis, University of Gothenburg, Sweden.

Wood, K. (2010). The potential of learning study for improving curriculum design, teaching and learning. Paper presented at World association of lesson studies (WALS) 2010 Conference, Brunei Darussalam.

Yoshida, M., \& Fernandez, C. (2004). Lesson Study. A Japanese approach to improving mathematics teaching and learning. Mahwah: Lawrence Erlbaum Associates Inc. 